\title{
TAHSP:-
}

The Internet Joưnal of Allied Health Sciences and Practice

A Peer Reviewed Publication of the College of Health Care Sciences at Nova Southeastern University

Dedicated to allied health professional practice and education

http://ijahsp.nova.edu Vol. 11 No. 4 ISSN 1540-580X

\section{Factors that Contribute to Failed Retention in Former Athletic Trainers}

\author{
Leamor Kahanov, PhD, ATC1 \\ Lindsey E. Eberman, PhD, ATC2 \\ Laura Juzeszyn, ATC ${ }^{3}$
}

1. Chair and Professor, Department of Applied Medicine and Rehabilitation, Indiana State University, Terre Haute, Indiana

2. Program Director and Associate Professor, Department of Applied Medicine and Rehabilitation, Indiana State University, Terre Haute, Indiana

3. Clinician, Department of Applied Medicine and Rehabilitation, Indiana State University, Terre Haute, Indiana

United States

CITATION: Kahanov L, Eberman LE, Juzeszyn L. Factors that Contribute to Failed Retention in Former Athletic Trainers. The Internet Journal of Allied Health Sciences and Practice. Oct 2013. Volume 11 Number 4.

\begin{abstract}
BACKGROUND: Athletic trainer retention has been topic of concern for 20 years, with one study indicating a drastic decline within ten years of becoming certified. Burnout, life-work balance, role strain, socialization, salary, in addition to other constructs are potential reasons for a lack of retention. An assessment of individuals who have left the athletic training profession is lacking; therefore, the purpose of this study was to discover the reasons why athletic trainers leave the profession of athletic training. DESIGN: Web-based survey. Qualtrics ${ }^{\circledR}$ was used to survey of 1000 individuals who let their athletic training certification lapse within 5 years of the study. SUBJECTS: Of the 198 (response rate $=23 \%$ ) respondents, the majority were female $(n=119,60 \%)$, married $(n=149,75 \%)$ with children $(n=127,64 \%)$. MAIN OUTCOME MEASURES: The survey included demographic information and 5-point Likert matrices of factors that contribute to retention. The data were analyzed for demographic and factor analysis information. RESULTS: The data suggests that items of burnout including clinical depression, role strain, ethical and social strain, feelings of sadness, hopelessness, and decreasing sleep consistently contribute to leaving the athletic training profession (44.8\% of variability). Employment factors accounted for $10.5 \%$ of the variability with variables such as travel demands, work hours, role overload, staffing, work environment, and lack of administrative support contributing to leaving the profession. Personal characteristics $(4.5 \%)$ and personal fit $(9.7 \%)$ also contributed variability in the data. CONCLUSIONS: Retention appears to be driven by some extrinsic (burnout and employment) and some intrinsic (personal characteristics and fit) variables. Additional inquiry into the personal factors for persistence may help to better identify those that are more likely to stay in athletic training.
\end{abstract}

\section{INTRODUCTION}

The U.S. Bureau of Labor anticipates an increased need (44\%) in athletic trainers through 2018, yet literature indicates that retention in athletic training is difficult. ${ }^{1,2}$ Athletic trainer retention has been a topic of concern for 20 years with one study indicating a drastic decline within ten years of becoming certified. ${ }^{2-4}$ Assertions as to why these individuals leave exist, but research directed specifically at individuals who have left the profession is lacking. Current literature suggests that travel requirements, long work weeks (up to 70 hours/week), coping with unplanned schedule changes, and stress-related factors like role-conflict, burnout, salary, and life-work balance challenges contribute to retention issues, but are also the nature of the profession. $3-15$ 
Athletic training shares these qualities with other service and health care professions such as coaching, emergency medical personnel, physicians, and nursing with similar assertions regarding burnout. Coaching has similar time demands as athletic training, and women leave the profession of coaching before men, because of a perceived lack of opportunity, discrimination, advantageous opportunities other than coaching, and time demands. ${ }^{16}$ With head coaching positions, work-family conflict appears greater.16 Emergency medical personnel often experience burnout likely as a result of emotional exhaustion.18 Demanding work schedules and shift work contributed to nurses leaving the profession. ${ }^{19}$ Nurses are experiencing burnout and leaving the practice due to stress, anxiety, low morale, heavy workloads, and decreased resources, as well as the added responsibility of serving as a preceptor. ${ }^{18,20} \mathrm{Job}$ demands are also an issue among health professionals, particularly among pediatricians. ${ }^{21}$ Although the literature indicates that athletic training, like coaching, emergency medical technicians, nursing, and physicians have challenges with role-conflict and life-work balance, an understanding of whether these issues contribute to decreased retention specific to that profession is unknown. Understanding the exact reasons why athletic trainers leave and professional direction after separation may enhance efforts in retention and education.

The domination of the athletic training profession by young, entry-level clinicians and the number of athletic trainers prematurely leaving the profession minimizes mature, seasoned professionals to model life-long work habits. ${ }^{1}$ Men leave the profession by the age of 35 while females leave the profession by the age of 28 , and a greater number of women leave the profession proportionally. ${ }^{1}$ Numerous theories have been proposed as to why these individuals have left the profession, but research conducted among these individuals is lacking. ${ }^{1-16}$ Thus, the purpose of this study is to discover the reasons why athletic trainers leave the profession of athletic training.

\section{METHODS}

\section{Participants}

One thousand individuals (18 years or older) who let their athletic training certification lapse within the last 5 years were contacted through email to participate. Access to the Board of Certification (BOC) public database was granted to access participants' names and email addresses. Individuals who are currently a certified athletic trainer, individuals who let certification lapse and have resubmitted certification, individuals who had their license revoked, and individuals who retired from the profession of athletic training were excluded from the participant pool. Of the 1000 individuals emailed participation letters, 189 were returned undeliverable for a total of 811 received requests for participation. A total of 198 (response rate $=24 \%$ ) of individuals completed the survey.

\section{Instrumentation}

The survey instrument was created based on current literature about retention and burnout.5-11 ${ }^{5 u a l t r i c s}{ }^{\circledR}$, which has been identified as an effective means of distributing surveys, was used to deliver the survey instrument to the former athletic training certified individuals. ${ }^{23-29}$ Three certified athletic trainers with a range of 6 to18 years of experience (mean=12 \pm 8.5 years) established face validity of the instrument. A principle component factor analysis was used to determine construct validity. Nineteen variables were analyzed. Component one were considered to group together for items that had a correlation of .65 or greater. Component two were considered to group together with a correlation of .5 to.65. Additional correlations were identified based on similar correlations and relevance to contribution to the variability of factors. The survey included 13 questions with eight demographic questions (age, gender, children, years as a certified athletic trainer, relationship status, last setting of employment, number of hours worked on average, and highest level of education received). The instrument included three matrixes. The first matrix queried individuals on life-work balance issues with 9 stems. Matrix two queried individuals on workrelated issues with six stems. Matrix three queried individuals on burnout symptoms with 10 stems. Each matrix employed a 5point Likert scale to assess agreement with either the reasons why individuals let their certification lapse, or feelings of burnout. Finally, two open-ended questions were included to elicit additional comments about the personal decisions to leave athletic training. Internal consistency of the survey instrument identified a Cronbach's alpha of .983.

\section{Procedures}

Institutional Review Board approval was obtained prior to survey dissemination. Participants were emailed a request to participate in the survey. The initial letter stated the study's purpose, the expectations of participation, and the risk/benefits of completing in the study. A three week window was allowed for survey completion. A reminder email was emailed to complete the survey on day 8 after initial contact. The survey was closed upon the conclusion of the three-week window. The data were gathered and statistically analyzed using a factor analysis to assess variable consistency and variability, and descriptive statistics to assess demographic and matrix stem data. 


\section{RESULTS}

One hundred and ninety eight individuals $(19 \%, 198 / 1000)$ responded and completed the questionnaire. The majority of respondents to the survey instrument were female $(n=119,60 \%)$. Males accounted for $38 \%(n=76)$, and three individuals did not indicate gender. Single individuals constituted $16 \%$ of participants $(n-31)$, with a majority married $(n=149,75 \%)$ or in a relationship $(n=11,5.6 \%)$. The majority of individuals who had left athletic training had children $(n=127,64 \%)$. One respondent did not answer the question, and $35 \%$ did not have children $(n=70)$. Employees that were employed in secondary schools constituted the majority $(n=58,29.3 \%)$, with clinics $(n=39,19.7 \%)$ and collegiate/university former athletic trainers $(n=36,18.2 \%)$ constituting most of the other respondents (Table 1).

\begin{tabular}{|l|r|r|}
\hline \multicolumn{1}{|c}{ Table 1. Athletic Trainer Former Employment Wetting Demographics } \\
\begin{tabular}{|l|r|r|}
\hline \multicolumn{1}{|c|}{ Former employment setting } & Frequency & Percent \\
\hline Junior College & 2 & 1.0 \\
\hline Division III/NAIA College/University & 11 & 5.6 \\
\hline Division II College/University & 6 & 3.0 \\
\hline Division I University & 17 & 8.6 \\
\hline Instructor/Professor/Researcher & 3 & 1.5 \\
\hline Amateur/Recreation/Youth Sports & 3 & 1.5 \\
\hline Clinic & 39 & 19.7 \\
\hline Health/Fitness/Sports Performance & 5 & 2.5 \\
\hline Hospital & 11 & 5.6 \\
\hline Independent Contractor & 1 & .5 \\
\hline Industrial/Occupational & 5 & 2.5 \\
\hline Military/Law Enforcement/Government & 1 & .5 \\
\hline Professional Sports & 4 & 2.0 \\
\hline Secondary School & 58 & 29.3 \\
\hline Unemployed & 3 & 1.5 \\
\hline Other (Please explain.) & 28 & 14.1 \\
\hline Missing & 1 & .5 \\
\hline Total & 198 & 100.0 \\
\hline
\end{tabular}
\end{tabular}

A principle component factor analysis was conducted to assess variable consistency. Ten factors were identified; however, only the first four were maintained, which held $69.4 \%$ of the variability. Factor one, labeled burnout, accounted for $44.8 \%$ of the variability. The data suggests that items of burnout including clinical depression, role strain, ethical and social strain, feelings of sadness, hopelessness, and decreasing sleep consistently contribute to leaving the athletic training profession (Table 2a). Employment factors accounted for $10.5 \%$ of the variability (Table $2 \mathrm{~b}$ ) with variables such as, travel demands, work hours, role overload, staffing, work environment, and lack of administrative support contributing to leaving the profession. Personal factors (Table 2c) contributed less (4.5\% variability), but included added responsibility at home and children. Personal fit for the profession which considered money, expectations, and personal skills and values accounted for only $2.7 \%$ of the variability (Table 2d).

Table 2a. Principle Component Matrix of Factors Contributing to Retention: Burnout Factors

\begin{tabular}{|l|r|}
\hline \multicolumn{1}{|c|}{ Variables } & \multicolumn{1}{|c|}{ Burnout } \\
\hline Diagnosis of clinical depression & .627 \\
\hline Role Strain - stress associated with expected roles/positions & .649 \\
\hline Stress/Unhappiness & .699 \\
\hline Role Strain & .704 \\
\hline Stress/Unhappiness & .642 \\
\hline Role Conflict - when you perceive roles and job expectations are contradicting & .655 \\
\hline Contradictory/excessive expectations & .604 \\
\hline Social Conflict & .652 \\
\hline Ethical Strain & .661 \\
\hline Unpredictable/disruptive events & .618 \\
\hline I often felt sad or down in the dumps. & .777 \\
\hline I felt that my future looked hopeless. & .655 \\
\hline
\end{tabular}




\begin{tabular}{|l|r|}
\hline I didn't care to do the things I used to do to make me happy. & .828 \\
\hline I had to push myself to get things done. & .757 \\
\hline I tended to see the negative rather than the positive side of things. & .833 \\
\hline I was not sleeping well. & .798 \\
\hline I felt anxious and worried. & .869 \\
\hline Life did not seem worth living. & .700 \\
\hline I felt like I was depressed. & .797 \\
\hline I was diagnosed with clinical depression. & .689 \\
\hline Decreased energy & .800 \\
\hline Overextended emotionally & .772 \\
\hline Feelings of depletion of emotional resources & .798 \\
\hline Loss of idealism & .838 \\
\hline Negative, callous, or detached response to others & .851 \\
\hline Feeling of incompetence & .801 \\
\hline Feeling like a failure & .826 \\
\hline Fatigue & .778 \\
\hline Overwhelming exhaustion & .798 \\
\hline Weariness & .818 \\
\hline Low energy & .810 \\
\hline Insomnia & .753 \\
\hline Feeling emotionally drained & .849 \\
\hline Feelings of boredom & .650 \\
\hline Anger & .868 \\
\hline Frustration & .685 \\
\hline Negative attitude about work & .725 \\
\hline Self-doubt & .628 \\
\hline Pessimistic thinking & .806 \\
\hline Withdrawal from colleagues & .789 \\
\hline Withdrawal from family and friends & .693 \\
\hline Desire to quit work & .766 \\
\hline Decrease in quality of work & .766 \\
\hline Decreased enthusiasm & .697 \\
\hline
\end{tabular}

Table 2b. Principle Component Matrix of Factors Contributing to Retention: Employment Factors

\begin{tabular}{|l|r|}
\hline \multicolumn{1}{|c|}{ Variables } & \multicolumn{1}{|c|}{ Employment } \\
\hline Irregular or long work hours & .576 \\
\hline Travel Demands & .598 \\
\hline Irregular/long work hours & .512 \\
\hline Travel Demands & .593 \\
\hline Staffing Issues & .620 \\
\hline Lack of administrative support & .528 \\
\hline Lack of understanding of roles and responsibilities by administration & .527 \\
\hline Role Overload - insufficient time to complete all of the expected role functions & .583 \\
\hline
\end{tabular}

Table 2c. Principle Component Matrix of Factors Contributing to Retention: Personal Factors

Table 2c. Principle Component Matrix of Factors Contributing to Retention: Personal Factors
\begin{tabular}{|l|r|}
\hline \multicolumn{1}{|c|}{ Variables } & Personal Factors \\
\hline Added responsibility at home & .690 \\
\hline Children/parenting responsibilities & .718 \\
\hline
\end{tabular}

Table 2d. Principle Component Matrix of Factors Contributing to Retention: Personal Fit Factors

\begin{tabular}{|l|r|}
\hline \multicolumn{1}{|c|}{ Variables } & \multicolumn{1}{c|}{ Personal Fit } \\
\hline Salary & .270 \\
\hline Role Incongruity - role obligations and personal skills/values are incompatible & -.262 \\
\hline Role Ambiguity - expectations of position are vague, unclear, or ill-defined & -.443 \\
\hline
\end{tabular}




\section{DISCUSSION}

Athletic training is currently encountering a reduction in professionals at a time of serious need for clinicians. ${ }^{2}$ The reduced numbers of athletic trainers, particularly females over the age of 40 , is concerning for the socialization and professional development. Women in this study indicated that they left the profession in their late 20s, which is consistent with current literature. ${ }^{2}$ However, previous literature has also suggested men change clinical settings, which may coincide with their underrepresentation in this investigation. ${ }^{2}$ The age of athletic training certification lapse may be due to family, children, and general burnout. Further investigation into the relationship between age, professional and personal aspirations, and departure from the profession is still an area to be investigated.

Literature in athletic training theorizes that college and secondary school settings may have lower retention rates because of the work environment and burnout.7,11,14 Life-work balance can be defined as the quality of life experience where individuals perceive they can adequately manage both personal lives and professional work demands. ${ }^{7}$ Currently practicing professionals have indicated that an inability to balance professional/identity roles labeled as role strain, role overload, organizational socialization, and additional or hidden teaching responsibility, lead to burnout among athletic trainers. 8,14 Burnout is further identified into three constructs of emotional exhaustion, de-personalization, and decreased personal accomplishment, and occurs through a combination of factors including long work hours, job demands, emotional exhaustion, number of years in the profession, aging, staffing issues, and inflexible schedules.7,11,14 Interestingly, these factors were segmented into differing constructs among those who have already left the profession in this investigation. The connection between work environment, life-work balance, and burnout are inherent, yet when asked, former athletic training professionals identify burnout as the key to leaving the profession, whereas work and life-work factors may contribute but are not the sole reason. Assessment of individuals who have complaints regarding work environment and life-work balance who choose to stay in athletic training or manage the roles have indicated that a good support system, understanding coworkers, and caring administration are essential for work/life stress management. 1,8,10 The key as to why some individuals manage these stressors more effectively may need to be assessed in terms of hardiness or personality.

Family has been a conflicting retention variable in the literature. 1,6 The findings suggest that approximately $5 \%$ of individuals who have left athletic training do so because of children and responsibilities at home. What is unclear is whether the burnout construct is compounded by role strain between family and work. Qualitative query of individuals who have left the profession may provide more robust answers to the connection between life-work balance, burnout, and professional retention. Past research has suggested that work/family obligations that include hours worked, schedule, staff patterns, travel, and work overload are related to overall unhappiness and constitute a significant portion of the variability in this investigation, but separately and not in combination. $1,8,10$ The supposition that burnout is related to personal and employment constructs identified by our factor analysis and as indicated in past literature should be further assessed.

Athletic training professionals find similar retention issues as other high stress, long-hours healthcare and medical communities. Professions including emergency medicine, nursing, and physicians all experience similar factors that can lead to retention issues. Nurses often experience burnout as a result of overwork. ${ }^{19}$ Primary care pediatricians experience decreased emotional well-being, decrease in personal accomplishments, depersonalization, work overload, and demanding, noisy parents. ${ }^{22}$ Emergency medicine professionals often experience high emotional exhaustion and high depersonalization because of increased patient flow and a crowded work environment, management issues, workload demands, and individual characteristics consisting of coping mechanisms, social development, and work environment. ${ }^{18}$ Although factors contributing to athletic training burnout mimics other health care professions, burnout is only one component of retention.

The athletic training profession appears to have a lower rate of retention than other health care professions ranging from approximately $6 \%-47 \%$ across nursing, emergency technicians, and physicians. ${ }^{23-29}$ Difference in retention between other healthcare professions and athletic training may, in part, be because of salary. ${ }^{31-34}$ Although salary was not specifically investigated, literature suggests that professions with high monetary compensation have higher retention rates even when professionals score low on satisfaction outcomes. ${ }^{31-34}$ Given that athletic trainers, comparatively, receive less compensation, the low satisfaction evaluated against compensation may increase the likelihood of departure from the profession. Pointed questions and future research should elucidate if this is the likely reason for final departure from the profession. The current study did not identify salary as an issue for individuals leaving the profession, which conflicts with past literature. ${ }^{14}$ Perhaps the differences in population between past literature and our findings among those who left the profession is the basis for the difference in findings.

(C) The Internet Journal of Allied Health Sciences and Practice, 2013 


\section{Limitations}

Although a return rate of $24 \%$ is acceptable, particularly when capturing individuals with retention issues, the results may not be generalizable to all individuals who have lapsed athletic training certification. Likewise, 198 respondents may not be sufficient for a factor analysis to generalize beyond the respondents in the current study.

\section{CONCLUSION}

Burnout, employment factors, personal factors, and personal fit accounted for $69.4 \%$ of the reasons for leaving the athletic training profession in this study. Burnout, in the previous literature, seems to have become an all encompassing construct for the reasons for dissatisfaction within the profession. However, in this investigation, burnout accounted for only part of the reason for departure among our participants. Employment factors including travel demands, work hours, role overload, staffing, work environment, and lack of administrative support also contributed to leaving the profession. Furthermore, personal factors and personal fit also contributed to departure.

Some of the key factors in determining retention are extrinsic, almost characteristic of the profession, while others are intrinsic and dependent upon the individual. The employment environment in more traditional athletic training settings may inherently provide the climate where a lack of administrative support and understanding for job demands exists, whereas clinical and nontraditional athletic training environments may provide a more stable approach to practice and lead to a reduction in retention rates. The removal of athletic trainers from athletic departments to academic, heath centers ,or risk management units may provide the administrative support, decrease in role strain based on a more stable reporting structure, and a more comprehensive health care staff to support the job requirements. Likewise, additional inquiry into the personal factors for persistence and hardiness as entrance or exit requirements may help to better identify students' abilities. Armed with information on individual persistence and hardiness, educators and mentors may be able to direct students into more appropriate job settings or identify those more likely to stay in athletic training when employers and support systems decrease the burnout and employment factors.

\section{REFERENCES}

1. Statistics BoL. Occupational Outlook Handbook, 2012-2013 Edition. In: Labor USDo, ed. 2012-2013 Edition ed. Washington, DC: BLS; 2010-2011:1-3.

2. Kahanov L, Eberman LE. Age, Sex, and Setting Factors and Labor Force in Athletic Training. Journal of Athletic Training. 2011;46(4):424-30. [PMC3419155]

3. Goodman A, Mensch JM, Jay M, French KE, Mitchell MF, Fritz SL. Retention and Attrition Factors for Female Certified Athletic Trainers in the National Collegiate Athletic Association Division I Football Bowl Subdivision Setting. Journal of Athletic Training. 2010;45(3):287-98. [PMID 20446843]

4. Capel SA. Attrition of athletic trains. Journal of Athletic Training. 1990;25(1):34-9.

5. Brumels K, Beach A. Professional Role Complexity and Job Satisfaction of Collegiate Certified Athletic Trainers. Journal of Athletic Training. 2008;43(4):373-8. [PMC 2474817]

6. Kahanov L, Loebsack AR, Masucci MA, Roberts J. Perspectives on Parenthood and Working of Female Athletic Trainers in the Secondary School and Collegiate Settings. Journal of Athletic Training. 2010;45(5):459-66. [PMC2938316]

7. Kania ML, Meyer BB, Ebersole KT. Personal and environmental characteristics predicting burnout among certified athletic trainers at National Collegiate Athletic Association institutions. Journal of Athletic Training. 2009 Jan-Feb 2009;44(1):58-66.

8. Mazerolle SM, Bruening JE, Casa DJ, Burton LJ. Work-Family Conflict, Part II: Job and Life Satisfaction in National Collegiate Athletic Association Division I-A Certified Athletic Trainers. Journal of Athletic Training. 2008;43(5):513-22. [PMC2547871]

9. Henning JM, Weidner TG. Role strain in collegiate athletic training approved clinical instructors. Journal of Athletic Training. 2008;43(3):275-83. [PMC 2386421]

10. Mazerolle SM, Bruening JE, Casa DJ. Work-Family Conflict, Part I: Antecedents of Work-Family Conflict in National Collegiate Athletic Association Division I-A Certified Athletic Trainers. Journal of Athletic Training. 2008;43(5):505-12.

11. Walter JM, Van Lunen BL, Walker SE, Ismaeli ZC, Oñate JA. An Assessment of Burnout in Undergraduate Athletic Training Education Program Directors. Journal of Athletic Training. 2009;44(2):190-6. [PMC 2657022]

12. Pitney WA. Organizational influences and quality-of-life issues during the professional socialization of certified athletic trainers working in the National Collegiate Athletic Association Division I setting. Journal of Athletic Training. 2006;41(2):189-95. [PMC1472645]

13. Mensch J, Crews C, Mitchell M. Competing Perspectives During Organizational Socialization on the Role of Certified Athletic Trainers in High School Settings. Journal of Athletic Training. 2005;40(4):333-40. [PMC 1323296]

14. Staurowsky E, Scriber K. An analysis of selected factors that affect the work lives of athletic trainers employed in accredited educational programs. Journal of Athletic Training. 1998;33(3):244-8. [PMC 1320431]

(c) The Internet Journal of Allied Health Sciences and Practice, 2013 
15. Reed S, Giacobbi Jr PR. The Stress and Coping Responses of Certified Graduate Athletic Training Students. Journal of Athletic Training. 2004;39(2):193-200. [PMID 15173872]

16. Cunningham GBSM. Occupational Turnover Intent Among Assistant Coaches of Women's Teams: The Role of Organization Work Experiences. Sex Roles. 2003;49(3/4):185.

17. Sagas MGD. Predicting Head Coaching Intentions of Male and Female Assistant Coaches: An Application of the Theory of Planned Behavior. Sex Roles. 2006;54(9/10):695.

18. Popa F, Raed A, Purcărea VL, Lală A, Bobirnac G. Occupational Burnout levels in Emergency Medicine - a nationwide study and analysis. Journal of Medicine \& Life. 2010;3(3):207-15.

19. Santucci J. Facilitating the transition into nursing practice: concepts and strategies for mentoring new graduates. Journal for Nurses in Staff Development. 2004;20(6):274-84. [PMID 15586092]

20. Race TK, Skees J. Changing Tides Improving Outcomes Through Mentorship on All Levels of Nursing. Critical Care Nursing Quarterly. April - June 2010 2010;33(2):163-74. [PMID 20234205]

21. Kushnir T, Cohen AH. Job structure and burnout among primary care pediatricians. Work. 2006;27(1):67-74. [PMID 16873982]

22. Kushnir T, Cohen AH. Positive and negative work characteristics associated with burnout among primary care pediatricians. Pediatrics International. 2008;50(4):546-51.[PMID 19143981]

23. American Health Care Association, Departmetn of Rsearch. Report of findings 2009 nursing facility staff retention and turnover survey. Washington, DC: BLS; 2011.

24. Brooks RG, Walsh M, Mardon RE, Lewis M, Clawson A. The roles of nature and nurture in the recruitment and retention of primary care physicians in rural areas: A review of the literature. Academic Medicine. 2002;77(8):790-8. [PMID 12176692]

25. Carpenter JE, Conwary-Morana P, Petersen R, Dooley B, Walters B, Wilder M. Engaging Staff in nursing Recruitment and Tetention Initiatives: A multihospital perspective. Journal of Nursing Administration. 2004;34(1):4-5. [PMID 14737027]

26. Escallier LA, Fullerton JT. Process and outcomes evlauation of retention strategies within a nursing workforce diversity project. Journal of Nursing Education. 2009;48(9):488-94. [PMID 19645372]

27. Moseley A, Jeffers L, Paterson J. The retention of the older nursing workforce: A literature review exploring factors and influence the retnetion and turnover ofolder nurses. Contemporary Nurse. 2008;30(1):46-56. [PMID 19072190]

28. Perkins BJ, DeTienne J, Fitzgerals K, Hill M, Harwell TS. Factors associated with workforce retention among emergency medical technicians in Montana. Prehospital Emergency Care. 2009;13(4):456-61. [PMID 19731157]

29. American Medical Group and Cejka Search. Physician turnover hits new high. http://www.cejkasearch.com/news/physicianturnover-hits-new-high-as-housing-and-stock-markets-recover/. 2013. Accessed 5/2/13.

30. Cowlishaw S, Evans L, McLennan J. Work-family conflict and crossover in volunteer emergency service workers. Work \& Stress. 2010;24(4):342-58.

31. Campbell N. The influence of motivation in recruitment and retention of rural and remote allied health professionals: a literature review. Rural Remote Health. 2012;12(2):1900. Epub 2012 Jun 21.[PMID 22845190]

32. Chung CE, Kowalski S. Job stress, mentoring, psychological empowerment, and job satisfaction among nursing faculty. $J$ Nurs Educ. 2012;51(7):381-8. doi: 10.3928/01484834-20120509-03. Epub 2012 May 9. [PMID 22588567]

33. Goetz K, Campbell SM, Broge B, Dörfer CE, Brodowski M, Szecsenyi J. The impact of intrinsic and extrinsic factors on the job satisfaction of dentists. Community Dent Oral Epidemiol. 2012;Apr 21. doi: 10.1111/j.1600-0528.2012.00693.x. [PMID 22519887]

34. McGillis Hall L, Lalonde M, Dales L, Peterson J, Cripps L. Strategies for retaining midcareer nurses. $\mathrm{J}$ Nurs Adm. 2011;41(12):531-7. doi: 10.1097/NNA.0b013e3182378d6c. [PMID 22094618] 